Supplement of Nat. Hazards Earth Syst. Sci., 15, 1821-1833, 2015

http://www.nat-hazards-earth-syst-sci.net/15/1821/2015/

doi:10.5194/nhess-15-1821-2015-supplement

(C) Author(s) 2015. CC Attribution 3.0 License.

(c) (1)

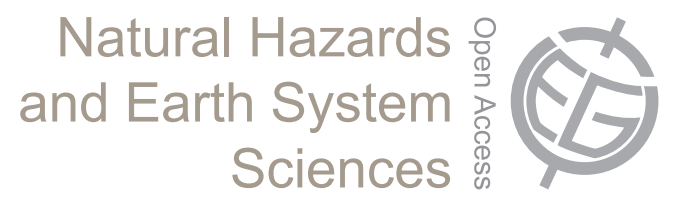

Supplement of

\title{
Regional trends and controlling factors of fatal landslides in Latin Amer- ica and the Caribbean
}

\section{S. A. Sepúlveda and D. N. Petley}

Correspondence to: S. A. Sepúlveda (sesepulv@ing.uchile.cl)

The copyright of individual parts of the supplement might differ from the CC-BY 3.0 licence. 

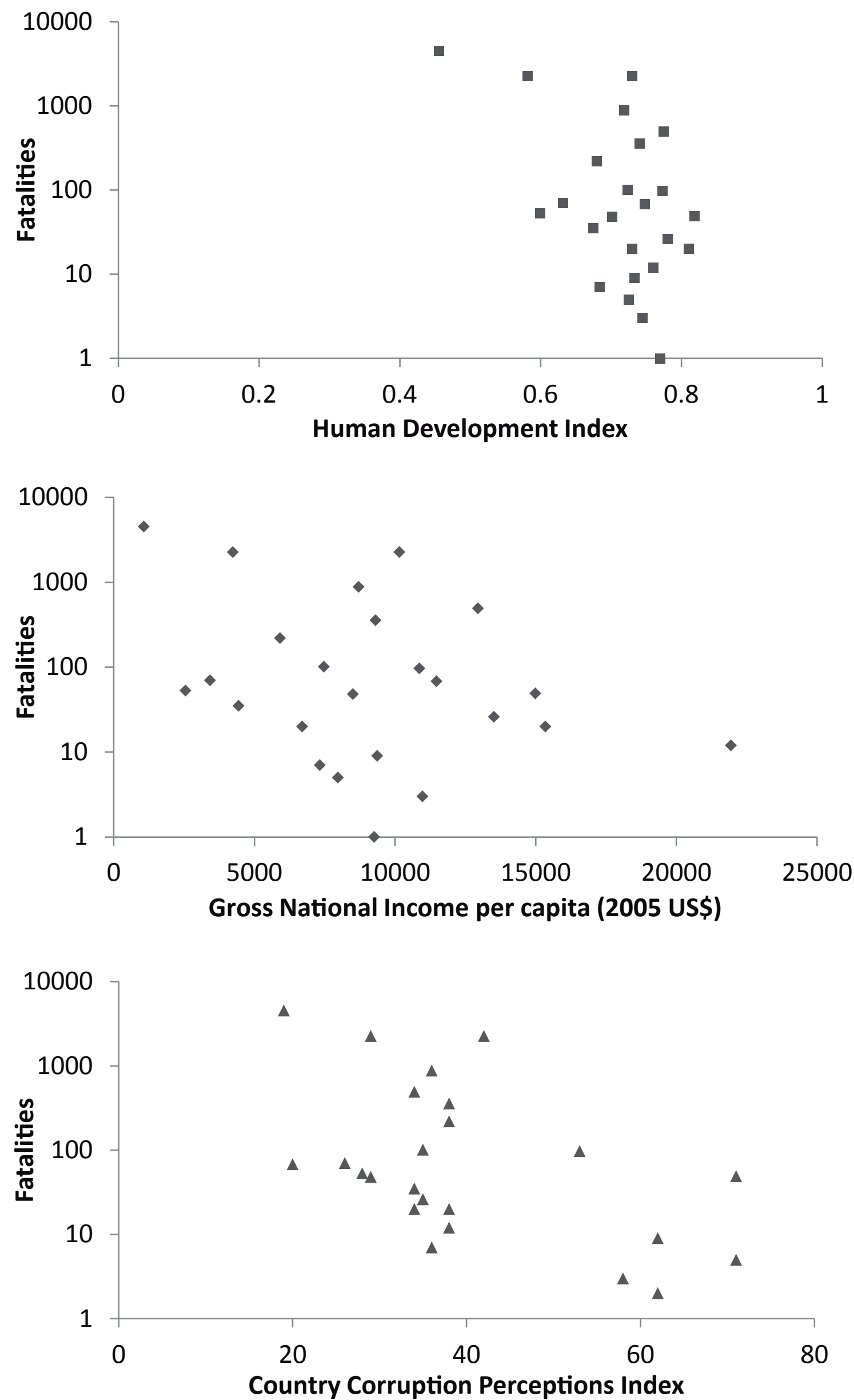

Figure S1. Relationship between fatalities induced by landslides and societal indexes of Human Development, Gross National Income and Country Corruption (UNDP, 2013; Transparency International, 2013). 